\title{
Estaquia de Ipomoea cairica (L.) Sweet
}

TOGNON, G.B. ${ }^{1}$; PETRY, C. ${ }^{2 *}$

${ }^{1}$ Produção Vegetal, Universidade Federal do Paraná (UFPR), Rua dos Funcionários, 1540, Juvevê, Caixa Postal 19061, CEP: 80035-050, Curitiba-Brasil gbtbio@gmail.com 2Produção vegetal, Universidade de Passo Fundo

(UPF), Campus I, Bairro São José, BR 285, Caixa Postal 611, CEP: 99.052-900, Passo Fundo-Brasil *petry@upf.br

RESUMO: A /pomoea cairica (L.) Sweet é uma trepadeira herbácea nativa, amplamente utilizada na medicina popular brasileira e inexistem informações sobre a propagação vegetativa. Em vista disso, objetivou-se avaliar a presença de folhas nas estacas, o substrato e a dose de reguladores vegetais mais adequados para a propagação por estaquia. Foram conduzidos dois experimentos, no primeiro, foram avaliados dois tipos de estacas (com e sem folhas) e quatro substratos (areia, casca de arroz carbonizada, latossolo vermelho distrófico + matéria orgânica - 1:1, latossolo vermelho distrófico + matéria orgânica + areia - 1:1:2), enquanto no segundo foram testadas cinco concentrações diferentes de AIB (0, 250, 500, 750 e $\left.1000 \mathrm{mg} \mathrm{L}^{-1}\right)$. Após 20 dias, obteve-se $86,2 \%$ de estacas enraizadas no substrato areia e, no segundo experimento, observou-se que 0 AIB não influenciou a porcentagem de enraizamento ( $94 \%$ em média). Conclui-se que a presença de folhas melhora a qualidade do enraizamento, que os substratos indicados para a propagação são areia e casca de arroz carbonizada devido ao maior enraizamento, fácil disponibilidade e baixo custo, e que a utilização de AIB na concentração $250 \mathrm{mg} \mathrm{L}^{-1}$ é a mais adequada para propagação por estaquia de $I$. cairica.

Palavras-chave: planta medicinal, propagação vegetativa, enraizamento, meio de crescimento, reguladores vegetais

ABSTRACT: Stem cutting of Ipomoea cairica (L.) Sweet. Ipomoea cairica (L.) Sweet is an herbaceous climbing plant widely used in Brazilian folk medicine and there is no information regarding its vegetative propagation. In view of this, the aim of this study was to evaluate the presence of leaves on stem cuttings and the most adequate substrate and level of plant growth regulators for propagation by stem cuttings of this morning glory. Two experiments were conducted, in the first, two types of stem cuttings (with and without leaves) and four substrates (sand; carbonized rice hull; Haplortox + organic matter - 1:1; Haplortox + organic matter + sand - 1:1:2) were evaluated, and in the second experiment five different concentrations of IBA $(0,250,500,750$ and $1000 \mathrm{mg} \mathrm{L}^{-1}$ ) were tested. After 20 days, we obtained $86.2 \%$ of cuttings rooted in sand substrate and in the second experiment IBA did not affect the rooting percentage ( $94 \%$ on average). We can conclude that the presence of leaves improved the quality of rooting, the substrates indicated for propagation are sand and carbonized rice hull due to greater rooting, easy availability and low cost, and the use of IBA at $250 \mathrm{mg} \mathrm{L}^{-1}$ is more appropriate to propagation by stem cuttings of $I$. cairica.

Key words: medicinal plant, vegetative propagation, rooting, growth medium, growth regulators

\section{INTRODUÇÃO}

A Ipomoea cairica (L.) Sweet, conhecida popularmente por Ipoméia, Jitiriana, Corriola, Campainha ou Corda-de-viola, é uma planta trepadeira herbácea, muito florífera e perene, sendo amplamente utilizada na medicina popular brasileira. A infusão feita com as folhas é utilizada popularmente no tratamento de erupções cutâneas, especialmente aquelas acompanhadas por febre. Remédios preparados com as raízes são usados na hepatite e, tanto as folhas quanto as raízes, têm ação purgativa (Alonso, 1988). Franco \& Fontana (1997) citam a utilização das partes aéreas da planta como anti-inflamatório e antireumático.

A maioria da população brasileira ainda é desprovida de recursos financeiros para tratar a saúde, motivo pelo qual o uso de plantas medicinais vem

Recebido para publicação em 08/12/2009

Aceito para publicação em 09/03/2012

Rev. Bras. PI. Med., Botucatu, v.14, n.3, p.470-475, 2012. 
crescendo nos últimos anos. Associado a valores culturais, existe uso imediato desses recursos pela população de baixa renda, o que gera menor necessidade de investimentos quando comparado a medicamentos sintéticos (Takahashi et al., 2006).

Os trabalhos relacionados à domesticação de plantas medicinais nativas são escassos ou, em muitos casos, inexistentes e com a crescente demanda da indústria farmacêutica são necessários estudos relacionados à propagação destas espécies para viabilizar a sua produção comercial. Segundo Hartmann et al. (2002), mesmo que a planta possa ser propagada sexualmente, a propagação vegetativa tem inúmeras vantagens por ser técnica simples, rápida e barata, produzir muitas mudas em espaço reduzido com maior uniformidade do estande e manter as características genéticas da planta doadora. Porém, o processo de enraizamento das estacas é influenciado por grande número de fatores, que podem atuar isoladamente ou em conjunto. Dentre eles destacamse as condições fisiológicas da planta matriz, o período de coleta das estacas, juvenilidade, estiolamento, presença de folhas e gemas, idade da planta matrize fatores do ambiente, tais como a disponibilidade de água, temperatura, luminosidade e substrato.

O tipo de substrato exerce influência significativa na formação do sistema radicial da estaca, sendo que o material ideal para a produção de mudas varia de acordo com a espécie a ser propagada e deve permitir bom suprimento de oxigênio e de água na base da estaca para o desenvolvimento de raízes. O substrato mais adequado deve ser inerte, poroso e com boa drenagem (Hartmann et al., 2002; Kämpf, 2005; Fermino \& Bellé, 2008).

O uso de reguladores vegetais para indução da formação de raízes varia de acordo com a espécie e o tipo de estacas, tanto em relação à concentração como ao tempo de imersão nessas soluções. As auxinas são os reguladores vegetais indicados para a indução de enraizamento e as mais importantes são o ANA (ácido naftaleno acético) e o AIB (ácido indolilbutírico), sendo este último bastante efetivo para o enraizamento de grande número de espécies (Grolli, 2008).

Em vista disso, amplia-se o interesse da pesquisa na propagação de plantas medicinais nativas. Estudos recentes tem-se concentrado na verificação dos melhores tipos de estacas e nos substratos mais adequados para o enraizamento, melhor distribuição e conformação das raízes, bem como, o efeito do uso de reguladores vegetais na indução do enraizamento. Assim, este trabalho teve como objetivo avaliar a presença de folhas nas estacas caulinares, o substrato e a dose de auxina mais adequada para a propagação por estaquia da Ipomoea cairica.

\section{MATERIAL E MÉTODO}

O experimento foi realizado em estufa do setor de Horticultura da Faculdade de Agronomia e Medicina Veterinária (FAMV) da Universidade de Passo Fundo (UPF) - localizada no município de Passo Fundo, RS, situado na região do Planalto Médio, norte do estado do Rio Grande do Sul, a 28 $8^{\circ} 5^{\prime}$ Sul e $52^{\circ} 24^{\prime}$ Oeste, a $687 \mathrm{~m}$ de altitude. O clima da região é caracterizado como subtropical $\mathrm{Cfa}$, de acordo com a classificação de Köppen, com chuvas bem distribuídas durante o ano e temperatura média anual em torno de $17^{\circ} \mathrm{C}$.

O trabalho foi conduzido em estufa de 210 $\mathrm{m}^{2}$, com $2,5 \mathrm{~m}$ de altura, em estrutura de alumínio galvanizado, teto em arco, revestida com polietileno de baixa densidade (PEBD), dotada de cortinas laterais móveis, instalada no sentido nordeste sudoeste. Para a redução da temperatura e insolação foi disposta internamente, a 2,5 m de altura e nas laterais, uma tela de sombreamento preta, com capacidade de $75 \%$ de sombreamento. O sistema de nebulização do tipo intermitente constou de seis linhas distanciadas de 1,5 m, com bicos nebulizadores dispostos a cada $1 \mathrm{~m}$. O sistema, controlado por um timer, era acionado a cada 10 minutos, com período de irrigação de 8 segundos.

Plantas de Ipomoea cairica (L.) Sweet foram coletadas a campo em março de 2009 e as estacas foram preparadas no Laboratório de Ecofisiologia de Plantas da FAMV, retiradas das partes medianas das plantas medindo $10 \mathrm{~cm}$ de comprimento com apenas um nó na parte superior da estaca.

\section{Experimento 1. Presença de folhas nas estacas e substratos}

Para a indução do enraizamento foram avaliadas quatro diferentes composições de substratos (areia, casca de arroz carbonizada - CAC; latossolo vermelho distrófico + matéria orgânica - 1:1, latossolo vermelho distrófico + matéria orgânica + areia - 1:1:2) em estacas com e sem folhas.

O delineamento experimental adotado foi completamente casualizado, em esquema fatorial 4 $x 2$, sendo quatro composições de substratos e dois tipos de estacas, com quatro repetições e oito estacas por parcela, num total de 256 estacas.

\section{Experimento 2. Cinco concentrações de ácido indolilbutírico (AIB)}

As estacas foram preparadas sem folhas e posteriormente tratadas com AIB diluído em álcool (70\%) para facilitar a posterior diluição e homogeneização em água destilada, nas concentrações de 0, 250, 500, 750 e $1000 \mathrm{mg} \mathrm{L}^{-1}$, imergindo $2 \mathrm{~cm}$ da base durante dez segundos. Em seguida foram colocadas em bandejas de poliestireno contendo como substrato casca de arroz carbonizada

Rev. Bras. PI. Med., Botucatu, v.14, n.3, p.470-475, 2012. 
e levadas à casa de vegetação.

O delineamento adotado foi completamente casualizado com cinco tratamentos e oito repetições, com seis estacas por parcela, totalizando 240 estacas.

As avaliações foram realizadas vinte dias após a instalação dos experimentos, observando-se o percentual de enraizamento, número de raízes, comprimento da maior raiz $(\mathrm{cm})$, número de folhas, massas frescas da parte aérea e da raiz e massa seca de raiz (em $\mathrm{mg}$ ).

Os dados foram interpretados por meio de análise de variância e as médias comparadas utilizando-se o teste Tukey a $5 \%$ de probabilidade, por meio do software SISVAR (Sistema de Análise de Variância para Dados Balanceados).

\section{RESULTADO E DISCUSSÃO}

\section{Experimento 1. Presença de folhas nas estacas e substratos}

Não se observou interação entre os diferentes tipos de substratos com a presença ou ausência de folhas (Tabela 1).

A presença de folhas nas estacas teve influência positiva nas variáveis (Tabela 1) comprimento da maior raiz, massa fresca da parte aérea, massa fresca de raiz e massa seca de raiz. Nas variáveis, porcentagem de enraizamento, número de folhas e número de raízes os tratamentos não diferiram estatisticamente, mas estacas com a presença de folhas apresentaram médias maiores com relação às estacas sem folhas. Esses resultados concordam com Oliveira et al. (2008) e Figueiredo et al. (2009), que testando diferentes tipos de estacas de Lippia sidoides obtiveram em estacas sem folhas a menor porcentagem de enraizamento.

A presença de folhas na estaca exerce forte influência estimuladora no enraizamento, pois os carboidratos resultantes da atividade fotossintética da planta também contribuem para a formação de raízes, embora os efeitos estimuladores da emissão de folhas e gemas devam-se, principalmente, à produção de auxina (Hartmann et al., 2002). Santos et al. (2009) observaram que estacas herbáceas de Aloysia gratissima apresentaram porcentagem maior de enraizamento do que estacas semi-lenhosas, devido ao fato que as estacas semi-lenhosas perderam as folhas, que serviram como fonte de auxinas para as estacas herbáceas, contribuindo para o melhor enraizamento. Esses fatos podem explicar os resultados encontrados em $I$. cairica onde a porcentagem de enraizamento das estacas com folhas mostraram-se maiores.

A porcentagem de estacas mortas foi baixa (menor que $1,1 \%$ ), mas indicou que a presença de folhas exerce uma influência negativa (Tabela 1), apresentando média maior do que as estacas

TABELA1. Análise de variância (quadrado médio) para as médias da porcentagem de enraizamento (PE), número de folhas (NF), número de raízes (NR), comprimento da maior raiz (CMR), massa fresca da parte aérea (MFPA), massa fresca de raiz (MFR), massa seca de raiz (MSR) e porcentagem de estacas mortas (EM), em estacas de Ipomoea cairica, em função dos diferentes substratos aos 20 dias após o transplante (FAMV, UPF, Passo Fundo, 2009).

\begin{tabular}{|c|c|c|c|c|c|c|c|c|c|}
\hline & \multicolumn{9}{|c|}{ QM } \\
\hline & $\mathrm{GL}$ & PE (\%) & $\mathrm{NF}$ & NR & CMR & MFPA & MFR & MSR & EM (\%) \\
\hline Substrato & 3 & $773,7^{\mathrm{P}=0,03}$ & $2,5^{\mathrm{P}=0,03}$ & 19,4 & 0,5 & 100723,0 & 510,8 & 9,0 & $4,0^{\mathrm{P}=0,01}$ \\
\hline Folhas & 1 & 180,5 & 0,7 & 28,1 & $24,5^{\mathrm{P}=0,001}$ & $744505,0^{P=0,01}$ & $2850,1^{P=0,02}$ & $104,5^{P=0,006}$ & $4,5^{\mathrm{P}=0,03}$ \\
\hline Substrato $x$ Folhas & 3 & 294,5 & 0,1 & 12,2 & 1,0 & 17704,6 & 536,0 & 16,2 & 2,1 \\
\hline Erro & 24 & 233,2 & 0,7 & 7,27 & 1,8 & 104889,9 & 516,5 & 11,5 & 0,8 \\
\hline Total & 31 & & & & & & & & \\
\hline Média & & 76,0 & 4,5 & 5,7 & 3,1 & 1055,9 & 18,3 & 4,0 & 0,7 \\
\hline CV (\%) & & 20,1 & 19,2 & 47,5 & 43,2 & 30,6 & 124,1 & 83,7 & 124,7 \\
\hline \multicolumn{10}{|l|}{ Tratamentos } \\
\hline A & & $86,2 \mathrm{a}$ & $5,3 a$ & 7,3 & 3,5 & 1123,3 & 18,2 & 4,1 & $0,2 \mathrm{~b}$ \\
\hline CAC & & $76,7 \mathrm{ab}$ & $4,1 \mathrm{~b}$ & 6,7 & 3,1 & 1178,1 & 29,6 & 5,4 & $0,2 \mathrm{~b}$ \\
\hline$S+M O(1: 1)$ & & $62,6 \mathrm{~b}$ & $4,2 a b$ & 4,1 & 2,8 & 973,1 & 12,7 & 3,0 & $1,7 \mathrm{a}$ \\
\hline $\mathrm{S}+\mathrm{MO}+\mathrm{A}(1: 1: 2)$ & & $78,3 \mathrm{ab}$ & $4,6 a b$ & 4,7 & 3,2 & 949,0 & 12,6 & 3,4 & $0,7 a b$ \\
\hline Com folha & & 78,3 & 4,7 & 6,6 & $4,0 a$ & $1208,8 \mathrm{a}$ & $27,7 \mathrm{a}$ & $5,8 a$ & $1,1 \mathrm{a}$ \\
\hline Sem folha & & 73,6 & 4,4 & 4,8 & $2,3 \mathrm{~b}$ & $903,37 \mathrm{~b}$ & $8,8 \mathrm{~b}$ & $2,2 \mathrm{~b}$ & $0,3 \mathrm{~b}$ \\
\hline
\end{tabular}

* Médias seguidas pela mesma letra na coluna não diferem significativamente entre si pelo teste Tukey ao nível de $5 \%$ de probabilidade. $\mathrm{A}=$ areia; $\mathrm{CAC}=$ casca de arroz carbonizada; $\mathrm{S}=$ solo; $\mathrm{MO}=$ matéria orgânica. 
sem folhas

O substrato areia apresentou melhores resultados na porcentagem de estacas enraizadas, diferindo estatisticamente apenas da mistura solo + matéria orgânica. $E$ também proporcionou maior número de folhas, diferindo estatisticamente somente da casca de arroz carbonizada. Não houve diferenças significativas entre substratos nas demais variáveis, exceto para porcentagem de estacas mortas onde a mistura solo + matéria orgânica teve efeito negativo (Tabela 1). Lima et al. (2003), em trabalhos de avaliação de três tipos de substratos (casca de arroz carbonizada, areia e solo) para produção de mudas de Mikania laevigata, constataram que o substrato casca de arroz carbonizada apresentou o melhor enraizamento, enquanto a menor taxa de enraizamento e maior índice de mortalidade foram obtidos no substrato solo; resultados semelhantes ao encontrados neste trabalho onde a presença de solo na mistura do substrato ocasionou maior mortalidade nas estacas.

Costa et al. (2007), testando diferentes substratos, areia, casca de arroz carbonizada e substrato comercial, para enraizamento de Ocimum selloi, não encontraram diferenças significativas entre eles. Para Hartmann et al. (2002) o meio de enraizamento ideal deve proporcionar porosidade suficiente para permitir uma boa aeração, ter alta capacidade para retenção de água e, não obstante, boa drenagem; relacionando esses fatores com os resultados obtidos nesse trabalho pode-se perceber que os substratos casca de arroz carbonizada e areia, os quais apresentaram as melhores porcentagens de enraizamento e menores taxas de mortalidade das estacas, possuem características de aeração e drenagem adequadas para a estaquia de $I$. cairica.

Concordando com os resultados desse trabalho, Almeida et al. (2008), em estaquia de Ixora coccinea mostram que a areia como substrato apresenta melhores condições para a formação de raízes. Igualmente, Lima et al. (2009) obtiveram os mesmos resultados testando substratos para a produção de Maytenus ilicifolia. O uso da areia como substrato apresenta vantagens para a produção de mudas, devido ao baixo custo, fácil disponibilidade e ainda apresenta características positivas quanto à drenagem para o enraizamento de estacas herbáceas (Fachinello et al., 1994).

Utilizando-se substrato comercial de origem organo-mineral e misturas de solo + casca de arroz carbonizada ou areia para enraizamento de Mentha arvensis, Paulus \& Paulus (2007) encontraram melhor resposta no enraizamento quando utilizado substrato comercial, mas nas conclusões indicam as misturas de solo + casca de arroz carbonizada ou areia por apresentarem resultados satisfatórios e serem materiais com custo mais baixo, lembrando que a casca de arroz é subproduto abundante da agroindústria arrozeira. Bona et al. (2005), em trabalhos com Baccharis articulata, B. trimera e $B$. stenocephala, obtiveram melhores resultados com uso de substrato comercial, não indicando para a produção destas espécies, o uso de solo, areia, vermiculita ou casca de arroz carbonizada, assim como Santos et al. (2009), que obtiveram melhor enraizamento de estacas de Aloysia gratissima com o uso de substrato comercial. Esses resultados diferem dos encontrados para I. cairica e mostra que cada espécie possui especificidades com relação ao substrato para enraizamento de estacas.

\section{Experimento 2. Cinco concentrações de ácido indolilbutírico \\ Estacas de Ipomoea cairica apresentaram} elevada porcentagem de enraizamento (entre $87,3 \mathrm{e}$ $97,8 \%$ ), independente do uso do AIB. A análise de variância apresentou valores significativos para número de folhas e de raízes, massa fresca da parte aérea e massa seca das raízes (Tabela 2). O maior número de folhas por estaca foi encontrado na concentração de $250 \mathrm{mg} \mathrm{L}^{-1}$, não diferindo estatisticamente das demais concentrações, com exceção de $1000 \mathrm{mg} \mathrm{L}^{-1}$, onde foi observado o menor número de folhas.

Para a variável número de raízes, o melhor resultado foi obtido na concentração de $500 \mathrm{mg} \mathrm{L}^{-1}$ só diferindo estatisticamente da testemunha e o comprimento da maior raiz não foi afetado pelo uso do regulador AIB. Figueiredo et al. (2009) afirmam que para a propagação assexuada de Lippia sidoides não há necessidade do uso de AIB para elevar a porcentagem de enraizamento, sendo que tal regulador vegetal apenas melhorou a qualidade das estacas enraizadas. Pimenta et al. (2007), em estudos com espécies não domesticadas de Lippia não encontraram efeito positivo no enraizamento com a adição de diferentes auxinas (AIB e ANA), contrastando com a facilidade de enraizamento de espécies de Lippia alba, onde a resposta da adição de reguladores foi positiva e acentuada.

A análise de variância mostra que para massa fresca da parte aérea se obteve melhores resultados nas concentrações de AIB a 250 e $500 \mathrm{mg} \mathrm{L}^{-1}$, para massa fresca de raiz a maior média foi para o tratamento com $500 \mathrm{mg} \mathrm{L}^{-1}$, mas não houve diferenças significativas entre os tratamentos. Para massa seca de raiz os melhores resultados foram encontrados na concentração de $500 \mathrm{mg} \mathrm{L}^{-1}$ mas diferindo apenas da testemunha.

De maneira geral, os dados obtidos no presente trabalho são semelhantes àqueles encontrados por Oliveira et al. (2008), que obtiveram maior porcentagem de enraizamento de estacas apicais com o uso da concentração de $250 \mathrm{mg} \mathrm{L}^{-1}$ de AIB para estacas de Lippia sidoides. 
TABELA 2. Análise de variância (quadrado médio) para as médias de porcentagem de enraizamento (PE), número de folhas (NF), número de raízes (NR), comprimento da maior raiz (CMR), massa fresca da parte aérea (MFPA), massa fresca de raiz (MFR) e massa seca de raiz (MSR) em estacas de Ipomoea cairica, em função dos diferentes doses de ácido indolilbutírico (AIB) aos 20 dias após o transplante (FAMV, UPF, Passo Fundo, 2009).

\begin{tabular}{|c|c|c|c|c|c|c|c|c|}
\hline & \multicolumn{8}{|c|}{ QM } \\
\hline & $\mathrm{GL}$ & PE (\%) & $\mathrm{NF}$ & NR & CMR & MFPA & MFR & MSR \\
\hline Doses de AIB (ppm) & 4 & 166,4 & $3,8^{P=0,001}$ & $31,6^{P=0,007}$ & 1,8 & $61846,4^{\mathrm{P}=0,0003}$ & 48,1 & $1,7^{\mathrm{P}=0,05}$ \\
\hline Erro & 35 & 136,1 & 0,6 & 7,6 & 1,5 & 9021,3 & 37,2 & 0,6 \\
\hline Total & 39 & & & & & & & \\
\hline Média & & 94,0 & 1,6 & 7,9 & 3,8 & 761,5 & 12,3 & 1,9 \\
\hline CV (\%) & & 12,4 & 52,0 & 34,7 & 32,5 & 12,4 & 49,53 & 42,4 \\
\hline \multicolumn{9}{|l|}{ Tratamentos } \\
\hline 0 & & 87,3 & $1,85 a$ & $5,62 \mathrm{~b}$ & 3,12 & $755,4 a b$ & 8,87 & $1,25 \mathrm{~b}$ \\
\hline 250 & & 95,7 & $2,37 \mathrm{a}$ & $7,87 \mathrm{ab}$ & 4,12 & 844,0 a & 12,87 & $1,75 a b$ \\
\hline 500 & & 97,8 & $1,50 a b$ & $11,12 \mathrm{a}$ & 3,87 & 837,0 a & 15,75 & $2,50 a$ \\
\hline 750 & & 97,8 & $1,75 a$ & $7,50 \mathrm{ab}$ & 4,37 & $744,5 a b$ & 12,00 & $2,12 a b$ \\
\hline 1000 & & 91,5 & $0,50 \mathrm{~b}$ & $7,62 \mathrm{ab}$ & 3,62 & $627,0 \mathrm{~b}$ & 12,12 & $1,87 a b$ \\
\hline
\end{tabular}

${ }^{*}$ Médias seguidas pela mesma letra na coluna não diferem significativamente entre si pelo teste Tukey ao nível de $5 \%$ de probabilidade.

Gratieri-Sossella et al. (2008) afirmam que o uso de AIB a partir de $1000 \mathrm{mg} \mathrm{L}^{-1}$, em estacas herbáceas de Erythrina crista-galli, reduz a mortalidade e favorece o enraizamento, quando utilizado em plantas jovens. Ferreira et al. (2009), em experimentos com estacas semi-lenhosas de Sapium glandulatum, obtiveram resultados satisfatórios com o uso de AIB concentrado, não indicando o uso de AIB diluído e o uso desse regulador na forma de talco. Neste trabalho não foram testadas o tempo de exposição ao regulador às auxinas concentradas ou aos reguladores na forma de talco; talvez esses apresentem melhores resultados em comparação a utilização de AIB na forma diluída sugerindo a aplicação desta metodologia para trabalhos futuros.

A partir dos resultados obtidos pode-se concluir que a presença de folhas em estacas de Ipomoea cairica (L.) Sweet. melhora o enraizamento das mesmas. O uso de areia e casca de arroz carbonizada como substratos são indicados para a propagação desta planta, pois, apresentam resultados satisfatórios no enraizamento, fácil disponibilidade, e baixo custo. É indicado o uso de AIB na concentração de $250 \mathrm{mg} \mathrm{L}^{-1}$, a qual foi mais adequada para a propagação de $I$. cairica por estaquia.

\section{AGRADECIMENTO}

Agradecemos à Capes pela concessão de bolsa de mestrado no PPGAGRO-UPF.

\section{REFERÊNCIA}

ALMEIDA, E.F.A. et al. Diferentes substratos e ambientes para enraizamento de mini-ixora (Ixora coccinea Compacta). Ciência \& Agrotecnologia, v.32, n.5, p.144953, 2008.

ALONSO, J.R. Estudios etnofarmacologicos del gênero Ipomoea. 1988. Disponível em: <www. plantas medicinales.org>. Acesso em: 20 jun. 2008.

BONA, C.M. et al. Estaquia de três espécies de Baccharis. Ciência Rural, v.35, n.1, p.223-6, 2005.

COSTA, L.C.B.; PINTO, J.E.B.P., BERTOLUCCI, S.K.V. Comprimento da estaca e tipo de substrato na propagação vegetativa de atroveran. Ciência Rural, v.37, n.4, p.1157-60, 2007.

FACHINELLO, J.C. et al. Propagação de plantas frutíferas de clima temperado. Pelotas: UFPel, 1994. 179p.

FERMINO, M.H.; BELLÉ, S. Substrato para plantas. In: PETRY, C. (Org.). Plantas Ornamentais: aspectos para a produção. 2.ed. Passo Fundo: EDIUPF, 2008. p.46-58. FERREIRA, B.G.A. et al. Metodologias de aplicação de AIB no enraizamento de estacas semilenhosas de Sapium glandulatum (Vell.) Pax. Revista Brasileira de Plantas Medicinais, v.11, n.2, p.196-201, 2009.

FIGUEIREDO, L.S. et al. Influência do ácido indolbutírico no enraizamento de alecrim-pimenta (Lippia sidoides) em leito com umidade controlada. Revista Brasileira de Plantas Medicinais, v.11, n.1, p.33-6, 2009.

FRANCO, I.J.; FONTANA, V.L. Ervas \& plantas: a medicina dos simples. Erechim: Livraria Vida, 1997. 208p.

GRATIERI-SOSELLA, A.; PETRY, C.; NIENOW, A.A. Propagação da corticeira do banhado (Erythrina cristagalli L.) (Fabaceae) pelo processo de estaquia. Revista Árvore, v.32, n.1, p.163-71, 2008.

GROLLI, P.R. Propagação de plantas ornamentais. In: 
PETRY, C. (Org.). Plantas ornamentais: aspectos para a produção. 2.Ed. Passo Fundo: EDIUPF, 2008. 201p. HARTMANN, H.T. et al. Hartmann and Kester's plant propagation principles and practices. 7.ed. Upper Saddle River, NJ: Prentice Hall. 2002. 880p.

KÄMPF, A.N. Substrato. In: KÄMPF, A.N. Produção comercial de plantas ornamentais. 2.ed. Guaíba: Agropecuária, 2005. p.45-72.

LIMA, D.M. et al. Enraizamento de miniestacas de espinheira-santa (Maytenus ilicifolia Mart. ex Reissek) em diferentes substratos. Ciência e Agrotecnologia, v.33, n.2, p.617-23, 2009.

LIMA, N.P. et al. Produção de mudas por estaquia de duas espécies de guaco. Horticultura Brasileira, v.21, p.106-9, 2003.

OLIVEIRA, G.L. et al. Enraizamento de estacas de Lippia sidoides Cham. utilizando diferentes tipos de estacas, substratos e concentrações do ácido indolbutírico. Revista Brasileira de Plantas Medicinais, v.10, n.4, p.127, 2008.

PAULUS, D.; PAULUS, E. Efeito de substratos agrícolas na produção de mudas de hortelã propagadas por estaquia. Horticultura Brasileira, v.25, p.594-7, 2007.

PIMENTA, M.R. et al. Floração, germinação e estaquia em espécies de Lippia L. (Verbenaceae). Revista Brasileira de Botânica, v.30, n.2, p.211-20, 2007.

SANTOS, F.M. et al. Produção de mudas de Aloysia gratissima (Gillies \& Hook.) Tronc. por meio da propagação sexuada e assexuada. Revista Brasileira de Plantas Medicinais, v.11, n.2, p.130-6, 2009.

TAKAHASHI, L.S.A.; ROCHA, J.N; SOUZA, J.R.P. Revisão sobre produção e tecnologia de sementes de espécies medicinais. Revista Brasileira de Plantas Medicinais, v.8, n.4, p.198-209, 2006. 